\title{
Religion and Spirituality in Pregnancy and Birth: The Views of Birth Practitioners in Southeast Nigeria
}

\author{
Magdalena Ohaja *(D), Jo Murphy-Lawless and Margaret Dunlea \\ School of Nursing and Midwifery, Trinity College Dublin, 24 D'Olier Street, D02 T283 Dublin, Ireland; \\ jlawless@tcd.ie (J.M.-L.); dunleama@tcd.ie (M.D.) \\ * Correspondence: ohajam@tcd.ie
}

Received: 15 November 2018; Accepted: 23 January 2019; Published: 28 January 2019

\begin{abstract}
Religion and spirituality have been acknowledged as crucial aspects of health and wellbeing. Nigeria, the most populous African country, is a multi-religious society where plural health systems (traditional and modern) co-exist. Religion is part of everyday conversation within the country and traditional healthcare providers are believed to have spiritual healing powers. Correspondingly, Nigerian women in their quest for a meaningful and comprehensive maternity care experience continue to use the plural health systems during the pregnancy birth continuum. Drawing from data collected through interviewing midwives $(n=7)$ and traditional birth attendants $(n=5)$, this paper explored the place of religion and spirituality within maternity care in the context of Igbo-Nigeria, through the lens of hermeneutic-phenomenology. Ethical approval was granted by relevant institutions and consent was obtained from each participant prior to the interviews. The findings revealed divergent views of the birth practitioners, influenced on one hand by conventional Western scientific ways of thinking, and on the other hand by traditional/cultural orientation. Healthcare professionals' views on the place of religion and spirituality within maternity care in Igbo-Nigeria reflect societal norms, impacting either positively or negatively on women's needs for a meaningful maternity care experience. In order to improve women's satisfaction with their pregnancy and birth experience, it is important for the healthcare providers to pay attention to and reflect on their own religious and spiritual belief systems.
\end{abstract}

Keywords: religion; spirituality; pregnancy and childbirth; cultural practices; Nigeria

\section{Introduction}

Nigeria, the most populous African country, is a religiously pluralised society with Christians found predominantly in the south, while the Muslims occupy most of the northern part of the country (Sampson 2014; Yesufu 2016). There are dual health systems (traditional and modern) which co-exist (Izugbara et al. 2005) with limited and often hostile interactions between the practitioners of both systems. Religion is part of everyday conversation within the country. (Nwoye 2011, p. 307) contends that the Igbo people have a religious conception of the world, one that has 'two planes; the physical and the spiritual.' In other words, for the Igbo people, the body, mind and spirit are connected, and this conception has its foundation in Igbo traditional religion, which involves communion between the physical and ancestral spirits (Iroegbu 2010; Ndubisi and Ogbuishi 2015). Indeed, traditional healthcare practices are shaped by beliefs in ancestral beings. In the words of (Sampson 2014, p. 316), 'the Igbo are, and have always been, a profoundly religious people who believe in a supreme creator, known as Chukwu.' As such for the Igbos, and other African cultures, there is no distinction between religion which seeks to explain the origin of humanity (Sampson 2014), values the sacredness of human life, and spirituality which is a way of being, a quest for 'meaning and purpose of life' 
(Akeredolu et al. 2017, p. 91). Possession of spiritual powers is 'common to all known religions' and is inherent among the Igbo people of Nigeria (Chukwukere 1983, p. 520).

Prior to the colonial period, the Igbo people practiced traditional religion characterised by rituals and sacred myths. The objects of worship in Igbo traditional religion include God, non-spirits and the ancestors. There is no one individual to preach to others. God the supreme being is in control of the world and all it contains, and the supreme being is worshiped in the shrines through small gods or divinities. In fact, invoking ancestral spirits in healing rituals is central to African traditional religion. The ancestral spirits act as intermediaries. As for contemporary religion, Christianity came to Igbo land during the colonial era. Unlike the Igbo traditional religion, the Christian ministers propagated the faith to their followers and God was worshipped in churches. In times of illness, the Igbo medicine man was consulted for counselling and healing (Okeke et al. 2017). Elements of this are still in evidence today.

Historically, women were cared for by traditional birth attendants (TBAs) who mainly rely on the use of herbal medicine (Izugbara et al. 2005; Ohaja and Murphy-Lawless 2017; Aziato and Omenyo 2018). Traditional healthcare practitioners are often referred to as native doctors/healers, and they were the only available healthcare providers in the pre-colonial period (Izugbara 2000). Ancient priest-physicians were known for their ability to provide physical healing as well as spiritual care (Rhys 2014). Thus, traditional medicines are believed to have both therapeutic effect and spiritual healing powers. The latter is often considered lacking in the modern medicalised environment (Asamoah-Gyadu 2014). Anthropological explorations of indigenous societies depict pregnancy and childbirth as both a sociocultural and spiritual phenomena (MacCormack 1994; Daviss 1997). It is not surprising then that the popularity of traditional healthcare providers among women during the pregnancy and childbirth continuum persists, despite the availability of modern healthcare systems (Izugbara et al. 2005).

Healthcare practices, including the ways of being during pregnancy and birth, changed during the colonial era. Christian missionaries who came with the colonial masters, though not all, condemned the use of herbal medicine, describing it as evil, and also condemned what they labelled as pagan practices (Asamoah-Gyadu 2014; Williams 2018). Indigenous or traditional midwifery was also viewed in disparaging terms. Central to the modernisation and evangelisation project of Christian missionaries was the relocation of childbirth from the home to the hospital setting (Williams 2018). In the institutional setting the medicalisation of pregnancy and childbirth flourished; and paved the way for more emphasis on the supposed objective physical or physiological aspect of the pregnancy and birth process, denigrating the women's subjective experiences, including their religious and spiritual care needs (Williams 2018).

Yet traditional healing continued to be a cornerstone within communities. Traditional healers and birth attendants use mainly herbs. They have no formal education, some learned from their relatives while others went through an apprenticeship style of training. In Igbo prayer houses, the ministers not only pray for divine intervention, but they also use traditional herbs (Adanikin et al. 2014). In contrast, modern healthcare practitioners have had formal education which is approved by the government, and as such they are considered legitimate practitioners. For the Igbo women, pregnancy and birth remain normal life events, hence the continuous use of traditional birthing homes. Western conceptions of religion, as noted by (Sered 1991, p. 15), created a dichotomy between the body and spirit which contribute 'to a glossing over of women's experience.' This can be attributed to the Western style of education of healthcare professionals. Even though modern healthcare is accorded superiority over traditional healthcare, women in most less-resourced nations continue to use both pragmatically, according to their individual needs and circumstances. Many women in Nigeria seek care from traditional birth attendants (Ohaja and Murphy-Lawless 2017), traditional healers and prayer houses. (Crowther and Hall 2015, p. 173) acknowledged the need to revisit 'contemporary approaches to spiritual care in midwifery' in order not to lose significant aspects of the pregnancy and birthing experience viewed as crucial by the women. Citing emergency baptism as an example, they recalled 
how spiritual and religious rituals were very much part of midwifery practices in the past, at a time when midwifery was viewed as a calling or vocation (Crowther and Hall 2015).

Recent years, however, have witnessed a resurgence of interest in religion, spirituality and spiritual healthcare (Rassoulian et al. 2016). With the emergence of an African independent church movement at the beginning of the 21st century, herbal medicines gained some sacramental values, and are now available from churches and local prophets (Asamoah-Gyadu 2014). It can be argued that even in the midst of pressures from proponents of biomedicine to abolish religious-based healthcare and traditional healing rituals, the latter has gained fresh momentum among the Igbo people of Nigeria (Williams 2018). According to Crowther et al. (2015), birth is a sacrament. (Callister and Khalaf 2010, p. 21) described childbirth as 'a sacred event.' It is the responsibility of the midwife to ensure that the 'sacrament of birth' is kept 'holy' (Gaskin 2002, pp. 270-71). There are limited studies that specifically explored birth practitioners' experiences and views on religion and spirituality in pregnancy and birth in Nigeria. This paper presents the views of professional midwives and traditional birth attendants about religion and spirituality during pregnancy and birthing in the context of southeast Nigeria. The overall study from which this paper is drawn explored the concept of safe motherhood from the perspective of women and birth practitioners in southeast Nigeria which consists of five states that are home for the Igbo ethnic group. As we noted above, the religious landscape of Igbo people changed from traditional religion to Christianity in the colonial era (Umezinwa 2014; Okeke et al. 2017). Similarly, the move from traditional community-based healthcare to modern hospital-based care was gradually adopted, though the latter did not completely replace the former (Williams 2018).

\section{Method}

\subsection{Participants}

All practicing midwives and TBAs in the study locations were eligible to participate in the study. A total of seven midwives recruited from two teaching hospitals in southeast Nigeria and five traditional birth attendants (TBAs) who were independent practitioners in one rural village participated in the study. One of the senior midwives acted as the gatekeeper. Her role was to help in creating awareness of the study. The midwives interested in the study voluntarily approached the interviewer (the first author) to share their views on the subject. The TBAs were approached via a women's leader in the village concerned and requested to participate in the study. The participants' years of experience ranges from nine to 28 for the midwives, and four to 16 for the TBAs (as independent practitioners). All the participants were female and Christians. Three of the midwives were working in the antenatal clinic, two in labour wards, while two were in the postnatal wards. In addition to their certificate in midwifery, one holds a diploma in public health, and one was completing an MSc in public health at the time of the study. The TBAs acquired their knowledge and skills through two to three years of an apprenticeship style of training in a formal private healthcare facility and/or by observing other TBAs.

\subsection{Materials and Procedure}

Information about the study was given to midwives in all core areas (antenatal, labour and postnatal wards) of the two hospitals by the first author who was also the interviewer. Data were gathered through semi-structured individual face to face audio recorded interviews lasting 30-60 min. The midwives were interviewed in one quiet room located in the hospital and the language use was primarily English. The interviews with the TBAs took place in a neutral location in the village hall and the interviews were conducted in the traditional Igbo language. These were later translated into English during transcription. The first author, who was also the interviewer, is a Nigerian and speaks Igbo fluently. Field notes were used during the interviews to note the key points made by the participants and were reiterated afterwards to ensure that they were correctly captured. All the interviews were dialogical in nature. 
Given that the overall study was conducted in part fulfilment of a PhD in midwifery, ethical approval was obtained from the Faculty of Health Science, Trinity College, Dublin, as well as two teaching hospitals which serve as referral centres for primary healthcare centres as well as privately established healthcare institutions. For the purpose of confidentiality and anonymity, all the participants were assigned codes.

\subsection{Design of the Study}

The study used a hermeneutic phenomenological approach. Hermeneutic phenomenology describes as well as interprets the phenomenon under investigation to make sense of it from the participants' point of view (Manning 2012). Phenomenology explores lived experiences, while hermeneutics is a practical art of understanding particularly required when the meaning of something is unclear and ambiguous (Gadamer 2004, 2006). As a profession, midwifery is closely aligned with phenomenology given that when providing care, midwives employ a comprehensive or holistic, humanistic and reflexive approach, paying attention to individual experiences (Doherty 2010), while at the same time acknowledging the socio-cultural context in which the experiences and understanding take place (Gadamer 2004).

\subsection{Analysis of Data}

The analysis of the data was thematically carried out. This entails reading the transcripts several times, noting the specific and unique phrases in the individual transcripts (Laverty 2003). It also involved going back and forth within the individual transcripts, what Gadamer (2004) referred to as the hermeneutic circle. This was followed by merging the salient points relating to how the participants viewed religion and spirituality. Even though religion and spirituality were not the primary focus of the overall study, these phenomena were mentioned as having influence in Igbo women's ways of being during pregnancy and birthing. The first author participated in numerous peer discussions and presented the preliminary findings of the study at international conferences (Ohaja 2014a, 2014b, 2014c), all of which enhanced the quality of the study.

\section{Results}

Three themes representing the midwives and traditional birth attendants' views emerged namely: 'reliance on God as the main care provider', 'spiritual belief: a barrier to seeking hospital-based care', 'merging religious/spiritual care with physical/medical care'. The latter can be seen as an attempt to go beyond the polarity in contemporary discourse around healthcare, that is, traditional versus modern.

\subsection{Reliance on God as the Primary Care Provider}

Some of the participants of the study saw God as the primary agent in caring for women during pregnancy and birthing. It is their belief that it is God who saves the lives of women under their care. In other words, the outcome of the pregnancy and birthing are dependent on the grace of God.

'Since the year 2000, I have not experienced any maternal death, thank God. God has been good and is preserving the lives of women who come to me.' (TBA2)

'God is good to His people, and he is the one preserving human life, only for him, we will be witnessing even worse conditions. Many women have died as a result of pregnancy and childbirth but thank God no woman has died under my care.' (TBA3)

One TBA with previous experience of neonatal death commented:

'I pray to God not to let me have such experience anymore. It was not nice at all. You feel as if God has left you, or He does not want you to continue the practice. For many years now, I have not had any death. So, I thank God for that.' (TBA5) 
For the TBAs who participated in this study, the work of caring for women during pregnancy and birthing is a divine call.

'I feel I am called into this area... Since I started my own practice, a lot of people are coming to receive care from me. Whatever is your gift or vocation you will do well in that job. Some people come to me after going to other places, and by the help of God they give birth under my care without any problem. I really feel this is my vocation. I am convinced that I am called into this kind of job.' (TBA1)

'Part of what I am doing is by God's gift and by God's grace. I really believe that this is a gift from God ... I started practicing since 1980 but I opened my own maternity home in 1996. As I said before, what I am doing is God's gift.' (TBA2)

Another said:

'It is really God's hand at work. It is not by our power.' (TBA4)

One midwife with 28 years of experience considers her profession a call from God.

'You see God has made us in different ways, personally I am a pastor's wife and I know that this work is a call.' (M5)

Two of the midwives described pregnancy as gift from God.

'To me it is a natural phenomenon that comes from God ..., So pregnancy is a normal phenomenon that comes from God ... it comes naturally.' (M4)

'It is a normal natural process that needs special care, and a gift from God that will need to be directed properly in order to receive God's blessing.' (M3)

Two other midwives acknowledged that women can give birth anywhere, including the prayer houses, in so far as there is no complication.

'Without complication, they will give birth wherever they are, in prayer houses ...

Another midwife noted:

'Most of the time the women do not come here, they prefer to go to prayer houses, and the traditional people...' (M7)

\subsection{Spiritual Belief: A Barrier to Seeking Hospital-Based Care}

Some of the participants, particularly midwives, perceived women's attendance in prayer houses to be a result of women's belief in supernatural forces. They expressed concern that this delays women from seeking timely hospital-based maternity care.

"... but if it is the unbooked women, you will see them going from one prayer house to another prayer house, ... they come here with complications." (M1)

Another midwife said:

'Unfortunately, ... You get some women who will not attend any place at all; they stay at home until late in pregnancy. When there is complication, they will start coming to the hospital and most of the time it is too late. We have a ward in this hospital full of unbooked women with one complication or the other. These are the women who never attended the antenatal clinic, but went to traditional people or prayer houses only to come to the hospital in a very bad condition.' (M7)

Another midwife made reference to women's beliefs in supernatural forces. 
'Some go to prayer houses ... they want to go to a prayer house; one woman abandoned her drugs, and went for prayers... Some will tell you that this disease/complication was sent i.e., sent by witches or evil forces, that is the language. It was a spiritual attack, you know ...

One TBA who encountered a complication during labour perceived it as being caused by the devil.

'I had an experience, a baby died immediately after birth. It was a very difficult birth; the devil was really at work that day. A baby boy with broad shoulders, he died. If the baby didn't die the woman would have died. This happened around the year 2000, since then I have not experienced any such thing.' (TBA3)

\subsection{Merging Religious/Spiritual Care with Physical/Medical Care}

The healing properties of traditional herbs work as long as those who use it have faith. One TBA stated:

'They (the women) believe so much in using traditional medicine ... you can prepare herbs like "nchuanwu" and they drink it with faith it works for them... I use both traditional and modern medicine.' (TBA2)

'We use drugs and herbs; it all depends on the condition. We treat people according to their need. In some cases, we use a combination of both. A lot of our natural herbs are effective.' (TBA1)

One midwife stated:

'We pray at the beginning of health talk (antenatal education) because we want God to be in control so that the care given to women will result in positive outcome.' (M6)

One midwife recalled how one woman who was transferred with a ruptured uterus, prayed for God to help healthcare practitioners to save her life. The midwife was also thankful to God that a doctor was around to deliver the medical care required to save the woman's life.

There was a day one woman was brought in I still remember, it is not just one, there are so many but let me just share this one .... Immediately they came into the accident and emergency department ..., they said (raised voice) ruptured uterus ..., the baby was crying by the side ... thank God for the doctor that was working there who was called, he came we were able to get one line put up normal saline ... this woman was pouring, I said to them start rushing her to the obstetric theatre, I myself with the woman's relative ... we wheeled her on the bed .... The woman said (low voice) please don't let me die because of my children, God help you people to save me ... We ended up in emergency hysterectomy ... The next two-three days this woman was sitting up and she was alive to care for the other ones that God have given her... (M5)

As a response to the question about managing complications, one of the TBAs said:

'You know sometimes the devil can attack, but by God's grace I have not encountered such problem.' (TBA 4)

Another said:

'By God's grace we don't experience much complication.' (TBA1)

The birth practitioners had differing views about religion and spirituality, as it relates to pregnancy and childbirth. Some participants, mostly the TBAs, perceived their work of caring as a call from God who for them is the primary agent and decider of pregnancy and birthing outcome. Others, particularly the midwives, perceived women's attendance in prayer houses during pregnancy to be largely influenced by belief in spiritual forces and therefore a barrier to seeking hospital-based care. Merging the religious/spiritual with medical care was considered a way forward. 


\section{Discussion}

Religion and spirituality are two prominent cultural elements that give meaning to human conducts, values and experiences (Ramezani et al. 2016). The Igbo people of Nigeria have a strong belief in the interconnectedness of the body, mind and spirit. The findings of this study revealed the need for birth practitioners to be conscious of religious and spiritual needs of women during pregnancy and birth. Reliance on the supreme God as the main care provider is among the themes that emerged from the study. Some of the participants of the study perceived their work as a call from God. In other words, their work has spiritual connection. Consequently, they have faith in the supreme God as the primary care provider, and under his guidance they carry out their duty of caring. This is typical of Igbo people's worldview, a world of complex sphere in which God is the supreme being (Chukwukere 1983; Nwoye 2011; Umezinwa 2014; Okeke et al. 2017). One of the midwives in our study who acknowledged her profession to be a call also stated that she is a pastor's wife. It is possible that her status as the wife of a pastor influenced her commitment. Nine out of ten midwives who took part in a study carried out by (Linhares 2012, p. 166) expressed 'belief in God as a higher being,' they also felt that their being a midwife was a divine call. Such belief can potentially enhance the care given to women, as it may heighten the practitioners' dedication and commitment.

In some cases, the interpretation of religious and spiritual practices in pregnancy and birth mirror the contemporary polarised discourse around the pregnancy birth continuum. For instance, delay in seeking prompt hospital-based maternity care is seen by midwives as a direct consequence of attending the traditional birthing homes and prayer houses. Even though similar findings exist in literature (Gyimah et al. 2006), it can be argued that such criticisms of religious and spiritual beliefs are influenced by conventional thinking that creates a dichotomy between modern and perceived non-modern beliefs and practices. Put differently, the spirituality of the colonial powers is at the forefront of contemporary analysis of religious and spiritual beliefs of indigenous communities. Similarly, by being too science-orientated, Western societies promote hospital-based maternity care, distancing pregnancy and birthing and its related practices from their original cultural and historic roots (Williams 2018). Akeredolu et al. (2017) reported that patients express their desire for clinicians to be aware of their religious and spiritual needs. Most importantly the health benefits of religious and spiritual care have also been documented, including psychosocial wellbeing, by extension fostering the concept of holism (Adanikin et al. 2014; Crowther and Hall 2015), awareness of the human nature of the unborn baby (Hall 2006), humanisation of care and the 'mysteriousness of our human existence' (Crowther and Hall 2015, p. 176). A recent study on the influence of religion on the use of maternal health services among Christian and Muslim women in Northern Nigeria showed that religion had minimal influence (Al-Mujtaba et al. 2016). However, the argument advanced by Williams (2018) and others is not uncontested.

Most of the TBAs in our study use both traditional herbs and modern medicine in order to offer comprehensive and meaningful care. Details of this aspect of the findings have been reported elsewhere (Ohaja and Murphy-Lawless 2017). It has been established that traditional herbs have therapeutic healing properties (Izugbara and Isong 2005; Asamoah-Gyadu 2014). Studies in Ghana show that TBAs use both spiritual and physical methods and that their work was founded on spiritual understandings (Aziato et al. 2016; Aziato and Omenyo 2018). Aziato and Omenyo (2018) in their qualitative interview of 16 TBAs in Ghana found that their practices go beyond physical care. In line with spiritual understandings on which their work is founded, they use spiritual artefacts and herbs depending on the needs of the women. Adetunji (1992) in an analysis of birth registers between 1983 and 1990 in the Yoruba area of southwest Nigeria, noted that 50 per cent of the births took place in a faith-based clinic with no formal Western medicine. Practitioners of the clinic totally relied on prayers, abstinence and direction from the Holy Spirit. TBAs' use of spiritual practices is also based on their belief that pregnant women are susceptible to spiritual attacks which may negatively affect the pregnancy (Adegoke and Jegede 2016) but can be prevented by offering spiritual care. 
In all, many of the participants made reference to praying to or thanking God for a positive outcome. Praying for and with women is a powerful way of addressing women's religious and spiritual needs. Midwives in a descriptive study by Linhares (2012) reported actively using prayer as a tool when supporting women during birth. This can be interpreted as one way of being with women, which is a core philosophy of midwifery practice. Izugbara and Isong (2005) reported that urban Igbo women sought care from both Western trained healthcare providers and rural-based herbalists and prayer homes for varied conditions including childbearing, infertility, menstrual problems among others. 'Spirituality relies on faith rather than scientific rigour. Science offers patients 'a $25 \%$ chance of recovery', whereas spirituality provides hope, support and comfort' (Rhys 2014, p. 4). There is an urgent need for birth practitioners to let go of what (Crowther and Hall 2015, p. 176) referred to as 'false dichotomies.' Incorporating religious and spiritual care, and medical care could be as described by (Adanikin et al. 2014, p. 6), 'an attracting force' to utilisation of hospital maternity services. This is a call for comprehensive approach to maternity care.

It can be argued that the data presented here are limited given the small sample size. The findings presented here may not be representative of the meanings of religion and spirituality for all birth practitioners. However, it has added insight to the existing literature. Midwifery is both a science and an art. As articulated by Mitchell and Jenny (2007), including religion/spirituality as a subject in midwifery education would go a long way in creating and increasing awareness of the religious and spiritual issues surrounding pregnancy and birth.

\section{Conclusions}

Religion and spirituality are two prominent cultural elements that give meaning to human conducts, values and experiences, and are inherent among Igbo people who have strong beliefs in the interconnectedness of the body, mind and spirit. The findings of this study revealed that despite the move to scientific-oriented maternity care, birth practitioners in southern Nigeria rely on God as the ultimate care provider. Some, including professional midwives, consider their work of caring for women to be a divine call. There are others who expressed concern over the potential negative impact of religious and spiritual beliefs. Teaching religion and spirituality to midwives and other healthcare professionals would be helpful in creating awareness of the possible positive impact of religion and spirituality. Integration of both religious and spiritual care, and physical/medical care, would enhance comprehensive or holistic care, as such ensuring that no aspect of care is ignored. This can be achieved if healthcare practitioners perceive that for women giving birth, it can be a sacred event. In all, the findings of this study highlight the need for birth practitioners to be conscious of religious and spiritual needs of women during pregnancy and birth. Therefore, it is important for the healthcare providers to pay attention to and reflect on their own religious and spiritual belief systems, or if they have any at all, compared with individual women for whom they might be caring. Given that religion and spirituality were not the central focus of the original overall study (Ohaja and Murphy-Lawless 2017), there is the need for further work that focuses specifically on this area, and that includes all maternity care providers.

Author Contributions: Conceptualization, M.O.; methodology, M.O.; formal analysis, M.O., J.M.-L, M.D..; investigation, M.O.; data curation, M.O.; supervision, J.M.-L.; project administration, M.O., All authors were equally involved in the writing of the manuscript.

Funding: This research received no external funding.

Conflicts of Interest: The authors declare no conflict of interest. 


\section{References}

Adanikin, I. Abiodun, Onwudiegwu Uche, and Akintayo A. Akinyemi. 2014. Reshaping maternal services in Nigeria: Any need for spiritual care? BMC Pregnancy and Childbirth 14: 1-6. [CrossRef] [PubMed]

Adegoke, Olufunke, and Ayodele Jegede. 2016. Continued patronage of traditional birth attendants (TBAs) by pregnant women in a traditional African community. Annals of Public Health Research 3: 3.

Adetunji, Jacob Ayodele. 1992. Church-based obstetric care in a Yoruba community, Nigeria. Social Science and Medicine 35: 1171-78. [CrossRef]

Akeredolu, Alimatu-Sadia, Harbinson T. Mark, and Bell David. 2017. Incorporation of spiritual care as a component of healthcare and medical education: Viewpoints of healthcare providers and trainees in Nigeria. The Nigerian Health Journal 13: 91-104.

Al-Mujtaba, Maryam, Cornelius J. Llewellyn, Galandanci Hadiza, Erekaha Salome, Okundaye N. Joshua, Adeyemi A. Olusegun, and Sam-Agudu A. Nadia. 2016. Evaluating religious influences on the utilization of maternal health services among Muslim and Christian women in North-Central Nigeria. BioMed Research International 2016: 3645415. [CrossRef] [PubMed]

Asamoah-Gyadu, Kwabena J. 2014. Therapeutic Strategies in African Religions: Health, Herbal Medicines and Indigenous Christian Spirituality. Studies in World Christianity 20: 70-90. [CrossRef]

Aziato, Lydia, and Cephas N. Omenyo. 2018. Initiation of traditional birth attendants and their traditional and spiritual practices during pregnancy and childbirth in Ghana. BMC Pregnancy and Childbirth 18: 1-11. [CrossRef]

Aziato, Lydia, Odai N.A. Philippa, and Omenyo N. Cepha. 2016. Religious beliefs and practices in pregnancy and labour: An inductive qualitative study among post-partum women in Ghana. BMC Pregnancy Childbirth 16: 138. [CrossRef]

Callister, Lynn Clark, and Inaam Khalaf. 2010. Spirituality in Childbearing Women. Journal of Perinatal Education 19: 16-24. [CrossRef]

Chukwukere, Ibe. 1983. Chi in Igbo Religion and Thought: The God in Every Man. Athropos 78: 519-34.

Crowther, Susan, and Jennifer Hall. 2015. Spirituality and spiritual care in and around childbirth. Women and Birth 28: 173-78. [CrossRef] [PubMed]

Crowther, Susan, Smythe Elizabeth, and Spence Deb. 2015. Kairos time at the moment of birth. Midwifery 31: 451-57. [CrossRef] [PubMed]

Daviss, Betty Anne. 1997. Heeding Warnings from the Canary, the Whale, and the Inuit: A Framework for Analyzing Competing Types of Authoritative Knowledge about Childbirth. In Childbirth and Authoritative Knowledge: Cross-Cultural Perspectives. Edited by Davis-Floyd E. Robbie and Sargent F. Carolyn. Berkeley: University of California Press, pp. 441-473. ISBN 0520206258.

Doherty, Mary E. 2010. Voices of midwives: The tapestry of challenges and blessings. MCN, The American Journal of Maternal/Child Nursing 35: 96-101. [CrossRef] [PubMed]

Gadamer, Hans Georg. 2004. Truth and Method, 3rd rev. ed. Translated by Joel Weinsheimer, and Donald G. Marshall. London: Continuum, ISBN O-8264-7697-X.

Gadamer, Hans George. 2006. Classical and philosophical hermeneutics. Theory, Culture E Society 23: 26-56.

Gaskin, Ina M. 2002. Spiritual Midwifery, 4th ed. Summertown: Book Publishing Company, ISBN 101570671044.

Gyimah, Stephen Obeng, Baffour K. Takyi, and Isaac Addai. 2006. Challenges to the reproductive-health needs of African women: On religion \& maternal health utilization in Ghana. Social Science E Medicine 62: 2930-44.

Hall, Jennifer. 2006. Spirituality of the unborn child. Journal of Clinical Nursing 15: 804-10. [CrossRef]

Iroegbu, Patrick E. 2010. Introduction to Igbo Medicine and Culture and Nigeria: Essays in Endogenous Medical System, Life and Culture. Canada: Lulu.com Publishing, ISBN 9780557263110.

Izugbara, Chima O. 2000. Women's understanding of factors affecting their reproductive health in rural Ngwa community. African Journal of Reproductive Health 2: 62-68. [CrossRef]

Izugbara, Chima O., and Afangideh Isong. 2005. Urban women's use of rural-based health care services: The case Igbo women in Aba city, Nigeria. Journal of Urban Health 82: 111-21. [CrossRef]

Izugbara, Chima O., Etukudoh J. Wilson, and Brown A. Sampson. 2005. Transethnic itineraries for ethnomedical therapies in Nigeria: Igbo women seeking Ibibio cures. Health and Place 11: 1-14. [CrossRef]

Laverty, Sussann M. 2003. Hermeneutic phenomenology and phenomenology: A comparison of historical and methodological considerations. International Journal of Qualitative Methods 2: 21-35. [CrossRef] 
Linhares, Carmen H. 2012. The lived experiences of midwives with spirituality in childbirth: Mana from heaven. Journal of Midwifery \& Women's Health 57: 166-71.

MacCormack, Carol P. 1994. Ethnography o/Fertility and Birth, 2nd ed. Prospect Heights: Waveland Press, ISBN 100881338176.

Manning, Lydia K. 2012. Spirituality as a lived experienced: Exploring the essence of spirituality for women late in life. International Journal of Aging in Human Development 75: 95-113. [CrossRef] [PubMed]

Mitchell, Mary, and Hall Jenny. 2007. Teaching spirituality to students midwives: A creative approach. Nurse Education in Practice 7: 416-24. [CrossRef] [PubMed]

Ndubisi, Ejikemeuwa J. O., and Anthony M. Ogbuishi. 2015. Religion and the Perception/Promotion of Human Life in Africa: Examining the Igbo of Southeastern Nigeria. Journal of Research in Business and Management 3: 42-48.

Nwoye, Chinwe M. A. 2011. Igbo cultural and religious worldview: An insider's perspective. International Journal of Sociology and Anthropology 3: 304-17.

Ohaja, Magdalena. 2014a. Socio-cultural aspects of safe/unsafe motherhood Optimising. Paper presented at the Childbirth Across Europe, Brussels, Belgium, April 9-10.

Ohaja, Magdalena. 2014b. The place of traditional births attendants within formal maternity care setting in South-east Nigeria: Midwives' perspective. Paper presented at the 30th ICM Triennial Prague Congress, Prague, Czech Republic, June 1-5.

Ohaja, Magdalena. 2014c. Co-existing belief systems of pregnancy and birth in South-eastern Nigeria and their influence on women's health-seeking behaviour. Paper presented at the Perception of Pregnancy from Medieval to 20th Century, Hartfield, UK, July 16-18.

Ohaja, Magdalena, and Jo Murphy-Lawless. 2017. Unilateral collaboration: The practices and understandings of traditional birth attendants in southeastern Nigeria. Women and Birth 30: e165-e171. [CrossRef] [PubMed]

Okeke, Chukwuma O., Ibenwa N. Christopher, and Okeke T. Gloria. 2017. Conflicts Between African Traditional Religion and Christianity in Eastern Nigeria: The Igbo Example. Sage Open 7: 1-10. [CrossRef]

Ramezani, Monir, Fazlollah Ahmadi, and Eesa Mohammadi. 2016. Spirituality in contemporary paradigms: An integrative review. Evidence Based Care Journal 6: 7-18.

Rassoulian, Anahita, Seidman Charles, and Loffer-Stastka Henrirette. 2016. Transcendence, religion and spirituality in Medicine. Medicine 95: 1-6. [CrossRef] [PubMed]

Rhys, Gwydion. C. 2014. Spiritual Discussion: Relevance, Benefits and Application to Primary Care Consultations. Primary Health Care 5: 178.

Sampson, Isaac T. 2014. Religion and the Nigerian State: Situating the de facto and de jure Frontiers of State-Religion Relations and its Implications for National Security. Oxford Journal of Law and Religion 3: 311-39. [CrossRef]

Sered, Susan S. 1991. Childbirth as a Religious Experience? Voices from an Israeli Hospital. Journal of Feminist Studies in Religion 7: 7-18.

Umezinwa, Cletus. 2014. The supreme being in the Igbo traditional religion in the south eastern Nigeria: A critical analysis. Asian Journal of Social Science \& Humanities 3: 59-65.

Williams, Ogechukwu E. 2018. A blur between the spiritual and the physical: Birthing practice among the Igbo of Nigeria in the Twentieth century. In Sacred Inception: Reclaiming the Spirituality of Birth in the Modern World. Edited by Elaporte Marianne and Martin Morag. London: Lexington Books, pp. 97-112. ISBN 1498546692.

Yesufu, Momoh L. 2016. The Impact of Religion on a Secular State: The Nigerian Experience. Studia Historiae Ecclesiasticae. pp. 1-11. Available online: http://www.scielo.org.za/pdf/she/v42n1/03.pdf (accessed on 3 October 2018).

(C) 2019 by the authors. Licensee MDPI, Basel, Switzerland. This article is an open access article distributed under the terms and conditions of the Creative Commons Attribution (CC BY) license (http://creativecommons.org/licenses/by/4.0/). 